\title{
Big Five Personality Traits and Creativity
}

\author{
DOI: 10.12776/QIP.V24I3.1509
}

\author{
Michal Jirásek, František Sudzina
}

Received: 2020-10-06 Accepted: 2020-10-26 Published: 2020-11-30

\begin{abstract}
Purpose: Personality traits represent an important driver of creativity. Several studies linked individual personality traits and creativity, yet in most cases, the literature provides contradictory insights. In this study, we quasi-replicate prior studies using a new sample to assess the reliability of previous research. Furthermore, we explore the topic in greater detail, as we also study the relationship of creativity with personality facets, a more fine-grained alternative.
\end{abstract}

Methodology/Approach: The study uses a survey-based sample of students from Denmark. To measure personality traits and facets, we asked respondents to fill 44 items Big Five Personality Inventory. We measured creativity using three items from the HEXACO-60 personality inventory. The data were analyzed using generalized least squares models with gender as a control.

Findings: In line with the previous literature, our research showed that Openness to Experience is positively related to creativity. We found similar, yet statistically weaker evidence for the relationship of Extraversion and creativity. In contrast to most of the previous findings, we also reported a negative relationship between Conscientiousness and creativity.

Research Limitation/Implication: Our research contributes to the topic of the relationship between personality traits and creativity. Some of the relationships fall into the area where the literature is not coherent. We propose that the explanation may stem from the too broad formulation of personality traits, and we partially show that using personality facets. For this reason, future research needs to go into detail of individual personality traits.

Originality/Value of paper: The paper provides further insight into the relationship between personality and creativity.

Category: Research paper

Keywords: Big Five; personality traits; creativity 


\section{INTRODUCTION}

The ability to innovate is an important prerequisite of the long term feasibility of organizations. However, what we observe as innovation is actually the result of two interlinked components - creativity and its implementation. Anderson, Poročnik and Zhou (2014, p.1298) described these two components as following: "The creativity stage of this process refers to idea generation, and innovation [implementation] refers to the subsequent stage of implementing ideas toward better procedures, practices, or products".

As they continue, we can speak of creativity (and innovation) on all the levels of the organization, including individuals. In previous years, this area has hosted various research topics (Feist, 1998; Karwowski and Lebuda, 2016; Puryear, Kettler and Rinn, 2017). One of the critical questions addressed is whether certain personality traits are exhibiting more creative or innovative behavior.

Our research focused on the above-mentioned research question and enriched our current understanding by a survey-based study of Danish students. Our study contributes to the field in two aspects. First, it quasi replicated previous research on the relationship between personality traits and creativity. As we show below in the literature review, current findings are far from conclusive for most of the traits. Second, we went into detail of individual personality traits and studied their distinctive facets. Both these aspects enrich our current understanding of whether and how is personality associated with creativity.

\section{LITERATURE REVIEW}

The question of how Big Five personality traits relate to creativity has been studied in several papers (see Table 1). They show that personality traits are systematically related to creativity. On the other hand, as evident from our overview, their findings are far from conclusive.

The question of the replicability of previous studies is a hot topic in psychology and related fields. Numerous researchers failed to replicate the results of previous studies, opening the debate about methodology and reporting practices. While we admit that in some cases, a fraud may be the core cause of a failure to replicate, Maxwell, Lau and Howard (2015) emphasized another issue. Failure to replicate may also be caused by the low statistical power of replication studies. For this reason, it is meaningful to replicate previous research in various settings and cumulatively built a body of findings on a given topic. 
Table 1 - Overview of Findings on the Relationship between Big Five Personality Traits and Creativity

\begin{tabular}{|c|c|c|c|c|c|}
\hline & Extraversion & Agreeableness & Conscientiousness & Neuroticism & $\begin{array}{c}\text { Openness } \\
\text { to } \\
\text { Experience }\end{array}$ \\
\hline $\begin{array}{l}\text { Sung and Choi } \\
\text { (2009) }\end{array}$ & + & $\begin{array}{c}\text { Not } \\
\text { significant } \\
(+)\end{array}$ & $\begin{array}{c}\text { Not } \\
\text { significant } \\
(-)\end{array}$ & $\begin{array}{c}\text { Not } \\
\text { significant } \\
(+)\end{array}$ & + \\
\hline $\begin{array}{l}\text { Batey, } \\
\text { Chamorro- } \\
\text { Premuzic and } \\
\text { Furnham (2010) }\end{array}$ & + & $\begin{array}{l}\text { Not } \\
\text { significant } \\
(-)\end{array}$ & - & $\begin{array}{c}\text { Not } \\
\text { significant } \\
(+/-)\end{array}$ & + \\
\hline $\begin{array}{l}\text { Furnham, } \\
\text { Hughes and } \\
\text { Marshall (2013) }\end{array}$ & + & $\begin{array}{l}\text { Not } \\
\text { studied }\end{array}$ & $\begin{array}{l}\text { Not } \\
\text { studied }\end{array}$ & $\begin{array}{l}\text { Not } \\
\text { studied }\end{array}$ & + \\
\hline $\begin{array}{l}\text { Hughes, } \\
\text { Furnham and } \\
\text { Batey }(2013)^{* *}\end{array}$ & $\begin{array}{c}\text { Not } \\
\text { significant } \\
\text { (not reported) }\end{array}$ & $\begin{array}{c}\text { Not } \\
\text { significant } \\
\text { (not reported) }\end{array}$ & $\begin{array}{c}\text { Not } \\
\text { significant } \\
\text { (not reported) }\end{array}$ & $\begin{array}{c}\text { Not } \\
\text { significant } \\
\text { (not reported) }\end{array}$ & + \\
\hline $\begin{array}{l}\text { Karkowski et } \\
\text { al. }(2013)^{* *}\end{array}$ & + & - & + & - & + \\
\hline $\begin{array}{l}\text { Kaufman and } \\
\text { Beghetto (2013) }\end{array}$ & $\begin{array}{c}\text { Not } \\
\text { significant } \\
\text { (not reported) }\end{array}$ & + & $\begin{array}{c}\text { Not } \\
\text { significant } \\
\text { (not reported) }\end{array}$ & $\begin{array}{l}\text { Not } \\
\text { reported }\end{array}$ & + \\
\hline $\begin{array}{l}\text { Silvia et al. } \\
\text { (2014) }\end{array}$ & $\begin{array}{c}\text { Not } \\
\text { significant } \\
(+)\end{array}$ & $\begin{array}{c}\text { Not } \\
\text { significant } \\
(+)\end{array}$ & + & $\begin{array}{c}\text { Not } \\
\text { significant } \\
(+)\end{array}$ & + \\
\hline $\begin{array}{l}\text { Stock, von } \\
\text { Hippel and } \\
\text { Gillert (2016) }\end{array}$ & $\begin{array}{c}\text { Not } \\
\text { significant } \\
(+)\end{array}$ & $\begin{array}{c}\text { Not } \\
\text { significant } \\
(+)\end{array}$ & $\begin{array}{c}\text { Not } \\
\text { significant } \\
(-)\end{array}$ & $\begin{array}{l}\text { Not } \\
\text { significant } \\
(-)\end{array}$ & + \\
\hline $\begin{array}{l}\text { Kaspi-Baruch } \\
\text { (2017) }\end{array}$ & $\begin{array}{c}\text { Not } \\
\text { significant } \\
(-)\end{array}$ & $\begin{array}{c}\text { Not } \\
\text { significant } \\
(+)\end{array}$ & $\begin{array}{c}\text { Not } \\
\text { significant } \\
(+)\end{array}$ & $\begin{array}{c}\text { Not } \\
\text { significant } \\
(+)\end{array}$ & + \\
\hline
\end{tabular}

Notes: ** Use Structural Equation Models (otherwise various forms of multivariate regressions).

Extraversion. "Extraversion describes the extent to which people are assertive, dominant, energetic, active, talkative, and enthusiastic," (Zhao and Seibert, 2006: 260). While six out of ten reviewed studies did not provide statistically significant results, the remaining four (Sung and Choi, 2009; Batey, ChamorroPremuzic and Furnham, 2010; Furnham, Hughes and Marshall, 2013; Karkowski et al., 2013) found a positive relationship between extraversion and creativity. This led us to pose the following hypothesis:

H1. Extraversion is positively related to creativity.

Agreeableness. "Agreeableness assesses one's interpersonal orientation. Individuals high on Agreeableness can be characterized as trusting, forgiving, caring, altruistic, and gullible," (Zhao and Seibert, 2006, p.260). Agreeableness 
represents one of the personality traits that is not clearly linked with creativity. Most of the studies we reviewed have not had significant findings. The only exceptions are Karkowski et al. (2013) (studying on self-reported creative selfefficacy and creative personal identity) who showed a negative relationship, and Kaufman and Beghetto (2013) (studying the perceived creative level of described products and people) positive. Based on the contradictory findings, we posed the following hypothesis:

\section{H2. Agreeableness is not related to creativity.}

Conscientiousness. "Conscientiousness indicates an individual's degree of organization, persistence, hard work, and motivation in the pursuit of goal accomplishment," (Zhao and Seibert, 2006, p.261). Conscientiousness provides another personality trait with contradictory findings. Out of three studies in our review that reported statistically significant findings, two (Karkowski et al. (2013), focusing on self-reported creative self-efficacy and creative personal identity; Silvia et al. (2014), focusing on real everyday creative activities) voted for positive relationship, while the remaining one (Batey, Chamorro-Premuzic and Furnham (2010), focusing on self-reported ideational behavior) voted otherwise. Based on the contradictory findings, we posed the following hypothesis:

\section{H3. Conscientiousness is not related to creativity.}

Neuroticism. "Neuroticism represents individual differences in adjustment and emotional stability," (Zhao and Seibert, 2006, p.260). Neuroticism is the trait that is the least linked with creativity in the previous research. Only Karkowski et al. (2013) reported a negative relationship in their study of creative self-efficacy and creative personal identity. Due to the fact that the majority of the literature has not provided conclusive findings, we posed the following hypothesis:

\section{H4. Neuroticism is not related to creativity.}

Openness to Experience. "Openness to Experience is a personality dimension that characterizes someone who is intellectually curious and tends to seek new experiences and explore novel ideas," (Zhao and Seibert, 2006, p.261). Openness to Experience is the only personality trait that has been unanimously confirmed by all reviewed studies. The reason is likely in the fact that it directly reflects creativity as apparent from its description. For this reason, we posed the following hypothesis:

H5. Openness to Experience is positively related to creativity. 


\section{METHODOLOGY}

Data were collected in the spring semester 2014 using an on-line questionnaire. Respondents were students of Aalborg University. Of 186 students who started, 170 (of whom 105 were male and 65 female) fully filled in the questionnaire and were included in our study sample.

Dependent variable:

- Creativity. We measured creativity using three items from HEXACO-60 personality inventory (Ashton and Lee, 2009). We used the mean of these items as our final measure of creativity. Specifically, we used items 13, 37, and 49:

- I would enjoy creating a work of art, such as a novel, a song, or a painting.

○ People have often told me that I have a good imagination.

○ I don't think of myself as the artistic or creative type.

Independent variables:

- Personality traits. The research presented in this paper is based on John and Srivastava's (1999) version of the Big Five Inventory questionnaire, which contains 44 statements (individual items are listed in the Appendix). The respondents rated statements on a 1-5 Likert scale where 1 means strongly disagree and 5 means strongly agree. To further explore individual personality traits, we also calculated 10 facets of them based on Soto and John (2009). These facets use 35 of the original 44 statements and are following (corresponding personality traits are in the brackets, details on individual items corresponding to them are again described in the Appendix):
○ Assertiveness (Extraversion),
- Activity (Extraversion),
- Altruism (Agreeableness),
○ Compliance (Agreeableness),
○ Order (Conscientiousness),
- Self-Discipline (Conscientiousness),
- Anxiety (Neuroticism),
○ Depression (Neuroticism),
- Aesthetics (Openness to experience),
- Ideas (Openness to Experience).

We used the means of corresponding items as the final measures. 
Control variable:

- Gender. We asked respondents to categorize themselves at either male (coded 0$)$ or female (coded 1).

A generalized least squares model (GLS) was used to analyze the impact of personality traits and their corresponding facets on creativity. All the calculations were conducted using $\mathrm{R}$ gls function (nlme package).

\section{RESULTS}

The descriptive statistics (means, standard deviations, and correlations) for the variables used in the model with personality traits are provided in Table 2. Multicollinearity is not an issue, with Variance Inflation Factors at 1.50 in their maximum (Neuroticism).

Table 2 - Descriptive Statistics Personality Traits

\begin{tabular}{|l|c|c|c|c|c|c|c|c|c|}
\hline \multicolumn{3}{|c|}{ Variables } & \multicolumn{7}{c|}{ Correlations } \\
\hline & Mean & SD & $(1)$ & $(2)$ & $(3)$ & $(4)$ & $(5)$ & $(6)$ & $(7)$ \\
\hline $\begin{array}{l}(1) \\
\text { Creativity }\end{array}$ & 2.918 & 0.796 & 1.000 & & & & & & \\
\hline $\begin{array}{l}\text { (2) } \\
\text { Extraversion }\end{array}$ & 3.312 & 0.411 & 0.270 & 1.000 & & & & & \\
\hline $\begin{array}{l}\text { (3) } \\
\text { Agreeableness }\end{array}$ & 3.620 & 0.442 & -0.037 & 0.086 & 1.000 & & & & \\
\hline $\begin{array}{l}\text { (4) } \\
\text { Conscientiousness }\end{array}$ & 3.547 & 0.498 & -0.092 & 0.054 & 0.274 & 1.000 & & & \\
\hline $\begin{array}{l}\text { (5) } \\
\text { Neuroticism }\end{array}$ & 2.615 & 0.534 & 0.002 & -0.299 & -0.323 & -0.180 & 1.000 & & \\
\hline $\begin{array}{l}\text { (6) Openness to } \\
\text { Experience }\end{array}$ & 3.374 & 0.451 & 0.597 & 0.298 & 0.081 & 0.110 & -0.145 & 1.000 & \\
\hline $\begin{array}{l}\text { (7) } \\
\text { Gender }\end{array}$ & 0.382 & 0.487 & 0.061 & 0.077 & 0.046 & 0.179 & 0.328 & -0.003 & 1.000 \\
\hline
\end{tabular}

Regarding the model with personality traits: First, Extraversion is weakly significant ( $\mathrm{p}$-value $=0.077$ ) and have a small positive effect (partial eta squared $=0.019$ ), providing weak support for H1. Second, Agreeableness is not significant ( $\mathrm{p}$-value $=0.592$ ), supporting $\mathrm{H} 2$ of no relationship. Third, Conscientiousness is clearly significant $(p$-value $=0.020)$ and have a medium negative effect (partial eta squared $=0.033$ ), against H3. Fourth, Neuroticism is not significant ( $\mathrm{p}$-value $=0.592$ ), supporting $\mathrm{H} 4$ of no relationship. Finally, five, Openness to Experience is significant ( $\mathrm{p}$-value $~ 0.000$ ) and have a large positive effect (partial eta squared $=0.345$ ), supporting H5. Gender was not significantly linked with creativity. 
Table 3 - GLS Model with Personality Traits

\begin{tabular}{|l|c|c|c|c|c|}
\hline & $\mathrm{B}$ & Std. Error & $\mathrm{t}$-value & $\mathrm{p}$-value & partial eta squared \\
\hline Intercept & -0.665 & 0.843 & -0.789 & 0.431 & \\
\hline Extraversion & 0.232 & 0.130 & 1.782 & 0.077 & 0.019 \\
\hline Agreeableness & -0.064 & 0.119 & -0.537 & 0.592 & 0.002 \\
\hline Conscientiousness & -0.245 & 0.104 & -2.351 & 0.020 & 0.033 \\
\hline Neuroticism & 0.096 & 0.110 & 0.871 & 0.385 & 0.005 \\
\hline Openness to Experience & 1.044 & 0.113 & 9.275 & 0.000 & 0.345 \\
\hline Gender & 0.101 & 0.111 & 0.908 & 0.365 & 0.005 \\
\hline $\mathrm{n}=170 ; \mathrm{R}^{2}=0.405 ;$ Adj. $\mathrm{R}^{2}=0.382 ; \mathrm{AIC}=351.719 ; \mathrm{BIC}=376.469$ & \\
\hline
\end{tabular}

Personality traits consists of facets. In case of the Big Five Inventory with 44 statements, there are two facets per trait (Soto and John, 2009). The descriptive statistics (means, standard deviations, and correlations) for the variables used are provided in Table 3. Multicollinearity is again not an issue, with Variance Inflation Factors at 1.54 in their maximum (Depression). 
Table 4 - Descriptive Statistics Personality Trait's Facets

\begin{tabular}{|c|c|c|c|c|c|c|c|c|c|c|c|c|c|c|}
\hline \multicolumn{3}{|c|}{ Variables } & \multicolumn{12}{|c|}{ Correlations } \\
\hline & Mean & SD & (1) & (2) & (3) & (4) & (5) & (6) & (7) & (8) & (9) & (10) & (11) & (12) \\
\hline $\begin{array}{l}\text { (1) } \\
\text { Creativity }\end{array}$ & 2.918 & 0.796 & 1.000 & & & & & & & & & & & \\
\hline $\begin{array}{l}\text { (2) } \\
\text { Assertiveness }\end{array}$ & 3.234 & 0.579 & 0.167 & 1.000 & & & & & & & & & & \\
\hline $\begin{array}{l}\text { (3) } \\
\text { Activity }\end{array}$ & 3.674 & 0.596 & 0.304 & 0.302 & 1.000 & & & & & & & & & \\
\hline $\begin{array}{l}\text { (4) } \\
\text { Altruism }\end{array}$ & 3.854 & 0.521 & 0.021 & 0.218 & 0.313 & 1.000 & & & & & & & & \\
\hline $\begin{array}{l}\text { (5) } \\
\text { Compliance }\end{array}$ & 3.294 & 0.600 & -0.045 & -0.088 & 0.107 & 0.313 & 1.000 & & & & & & & \\
\hline (6) & 3.368 & 0.759 & -0.170 & 0.004 & 0.139 & 0.265 & 0.019 & 1.000 & & & & & & \\
\hline $\mid \begin{array}{l}\text { (7) } \\
\text { Self-Discipline }\end{array}$ & 3.508 & 0.553 & -0.086 & 0.028 & 0.230 & 0.226 & 0.106 & 0.510 & 1.000 & & & & & \\
\hline $\begin{array}{l}\text { (8) } \\
\text { Anxiety }\end{array}$ & 2.646 & 0.696 & -0.024 & -0.195 & -0.291 & -0.094 & -0.107 & 0.021 & -0.058 & 1.000 & & & & \\
\hline $\begin{array}{l}(9) \\
\text { Depression }\end{array}$ & 2.535 & 0.689 & 0.117 & -0.289 & -0.288 & -0.328 & -0.235 & -0.294 & -0.240 & 0.278 & 1.000 & & & \\
\hline $\begin{array}{l}\text { (10) } \\
\text { Aesthetics }\end{array}$ & 3.006 & 0.693 & 0.495 & 0.088 & 0.224 & -0.032 & 0.027 & -0.066 & 0.082 & -0.025 & 0.119 & 1.000 & & \\
\hline $\begin{array}{l}(11) \\
\text { Ideas }\end{array}$ & 3.498 & 0.516 & 0.369 & 0.187 & 0.354 & 0.229 & -0.009 & 0.053 & 0.130 & -0.200 & -0.055 & 0.318 & 1.000 & \\
\hline $\begin{array}{l}(12) \\
\text { Gender }\end{array}$ & 0.382 & 0.487 & 0.061 & 0.025 & 0.066 & 0.063 & 0.045 & 0.138 & 0.197 & 0.310 & 0.162 & 0.139 & -0.079 & 1.000 \\
\hline
\end{tabular}

Results of the GLS model indicated three personality facets that are significantly related to creativity (i.e. are below 0.1 threshold for p-value). All of them Activity, Aesthetics, and Ideas - are positively related with p-values 0.005, 0.000 , and 0.006 . Activity have a medium positive effect (partial eta squared $=$ 0.048 ); Aesthetics a large positive effect (partial eta squared $=0.151$ ); and Ideas a medium positive effect (partial eta squared $=0.046$ ). Gender was again not significantly linked with creativity. 
Table 5 - GLS Model with Personality Traits' Facets

\begin{tabular}{|l|c|c|c|c|c|}
\hline & $\mathrm{B}$ & Std. Error & $\mathrm{t}$-value & $\mathrm{p}$-value & partial eta squared \\
\hline Intercept & -0.166 & 0.825 & -0.201 & 0.841 & \\
\hline Assertiveness & 0.093 & 0.098 & 0.948 & 0.345 & 0.006 \\
\hline Activity & 0.288 & 0.102 & 2.830 & 0.005 & 0.048 \\
\hline Altruism & -0.001 & 0.115 & -0.008 & 0.993 & 0.000 \\
\hline Compliance & -0.042 & 0.093 & -0.449 & 0.654 & 0.001 \\
\hline Order & -0.113 & 0.081 & -1.383 & 0.169 & 0.012 \\
\hline Self-Discipline & -0.168 & 0.110 & -1.523 & 0.130 & 0.014 \\
\hline Anxiety & 0.078 & 0.083 & 0.941 & 0.348 & 0.006 \\
\hline Depression & 0.089 & 0.090 & 0.983 & 0.327 & 0.006 \\
\hline Aesthetics & 0.425 & 0.080 & 5.291 & 0.000 & 0.151 \\
\hline Ideas & 0.312 & 0.113 & 2.769 & 0.006 & 0.046 \\
\hline Gender & 0.025 & 0.117 & 0.215 & 0.830 & 0.000 \\
\hline $\mathrm{n}=170 ; \mathrm{R}^{2}=0.373 ;$ Adj. $\mathrm{R}^{2}=0.330 ;$ AIC $=387.594 ; \mathrm{BIC}=427.408$ & & \\
\hline
\end{tabular}

\section{DISCUSSION AND CONCLUSION}

When comparing our findings with the previous literature, we added to the overwhelming evidence that Openness to Experience is a personality trait most directly linked with creativity. We also showed that Extraversion weakly increases creativity. In this trait, the literature is not unified. The cause may lie in the fact that two facets that constitute Extraversion - Assertiveness and Activity - do not both explain creativity, as we showed in our analysis.

Nevertheless, arguably the most unexpected results are the negative relationship of Conscientiousness and creativity. In this case, most of the literature did not report significant findings, while our sample demonstrated a highly significant association. This corresponded only to the study of Batey, Chamorro-Premuzic and Furnham (2010), while directly contradicted Karkowski et al. (2013) and Silvia et al. (2014). What is also interesting that this time, neither of the trait's facets - Order and Self-Discipline - drove the relationships with creativity directly. Our post-hoc analysis showed that creativity is linked only to some of the items of Conscientiousness personality trait (reversed items 18, 28, and 43 of 44-items Big Five Personality Inventory, see Appendix for these items). Therefore, it appears that similar to Extraversion, Conscientiousness needs to be narrowed down in investigation of creativity.

The study contributes to the literature on the relationship between personality and creativity, which is, in turn, a part of broadly defined creativity research (e.g., 
Kaufman and Sternberg, 2010). The influence of personality on creativity is now a well-established fact rooted in individual brain characteristics (e.g., Feist, 2010). Notwithstanding, creativity is only one of the key components of innovativeness and the ensuing innovation performance of individuals and organizations. While the relationship between Big Five personality traits and creativity has been a popular topic in the literature (see Table 1), research on innovativeness has been scarce. A comprehensive picture is given by the study of Stock, von Hippel and Gillert (2016), who followed the effect of personality traits on success in an innovation process (they distinguished three stages: idea generation, prototyping, and diffusion). They concluded that personality traits leading to a successful conclusion of a given stage differed over the innovation cycle. That points to an important implication for organizations that want to be more creative. Although it is arguably possible to increase creativity by hiring employees with particular personality traits (i.e., those that are open to experience, extravert but not conscientious), this would not perfectly translate into innovativeness. Not wasting one's creativity, therefore, means to complement her or him with someone with a different personality. That means someone who will translate creative ideas into actual products.

The main limitation of our study stems from its method, namely self-reported measures. However, self-reports are a standard approach used in the literature (all of the reviewed studies use self-reports for personality traits, and most of them also for creativity). One the other hand, this limitation also creates an opportunity for studies using personality traits that are assessed externally by other people, in the best case experts. Another limitation lies in the fact that we used only 35 out of $44 \mathrm{BFI}$ items for the calculation of personality facets (see the Appendix). This implies that the observed relationships in models with personality traits may differ from the observed relationships in models with personality facets due to structural reasons. Nevertheless, since Soto and John (2009) worked with the original 44-items scale when establishing these calculations, we believe that such structural differences have only a limited effect on our findings.

We agree with the conclusion of Anderson, Potočnik and Zhou (2014) that the relationship between personality traits and creativity is complex and likely shaped by numerous contextual factors (as shown in, e.g., research of Raja and Johns, 2010). Besides Openness to Experience (Aesthetics and Ideas facets) that directly reflect the personality and for which there is strong evidence in the literature, other personality traits represent a more difficult question. We believe that a more detailed focus on facets may bring in more insight, as we showed in the case of Activity facet. While in our study, Extraversion is only weakly related to creativity, Activity shows a very strong relationship. Besides contextual factors, this may provide another explanation of contradictory findings of the literature.

In conclusion, the relationship between personality traits and creativity is likely to be complex. In our study, we focused on an empirical test of the effect of Big Five Inventory personality traits on creativity. We showed the statistical 
significance of two of the traits that seem to be the most closely linked to creativity by previous studies: Openness to Experience and Extraversion. Furthermore, we showed a negative relationship between Conscientiousness and creativity. Finally, our analysis of personality traits' facets indicated that for some of the personality traits, more fine-grained measures are needed if we want to link them with creativity directly.

\section{ACKNOWLEDGEMENTS}

The research is supported by the Masaryk University research project MUNI/A/1073/2019 Behavioral aspects of organizations.

\section{REFERENCES}

Anderson, N., Potočnik, K. and Zhou, J., 2014. Innovation and creativity in organizations: A state-of-the-science review, prospective commentary, and guiding framework. Journal of Management [e-journal], 40(5), pp.1297-1333. doi: 10.1177/0149206314527128.

Ashton, M.C. and Lee, K., 2009. The HEXACO-60: A Short Measure of the Major Dimensions of Personality. Journal of Personality Assessment [e-journal], 91(4), pp.340-345. doi: 10.1080/00223890902935878.

Batey, M., Chamorro-Premuzic, T. and Furnham, A., 2010. Individual Differences in Ideational Behavior: Can the Big Five and Psychometric Intelligence Predict Creativity Scores? Creativity Research Journal [e-journal], 22(1), pp.90-97. doi: 10.1080/10400410903579627.

Feist, G.J., 1998. A meta-analysis of personality in scientific and artistic creativity. Personality and Social Psychology Review [e-journal], 2(4), pp.290309. doi: $10.1207 \% 2 F s 15327957$ pspr0204_5.

Feist, G.J., 2010. The function of personality in creativity. In: J.C. Kaufman and R.J. Sternberg eds., 2010. The Cambridge Handbook of Creativity. Cambridge University Press. pp.113-130.

Furnham, A., Hughes, D.J. and Marshall, E., 2013. Creativity, OCD, Narcissism and the Big Five. Thinking Skills and Creativity [e-journal], 10, pp.91-98. doi: 10.1016/j.tsc.2013.05.003.

Hughes, D.J., Furnham, A. and Batey, M., 2013. The structure and personality predictors of self-rated creativity. Thinking Skills and Creativity [e-journal], 9, pp.76-84. doi: 10.1016/j.tsc.2012.10.001.

John, O.P. and Srivastava, S., 1999. The Big Five trait taxonomy: History, measurement, and theoretical perspectives. Handbook of Personality: Theory and Research, 2, pp.102-138. 
Karwowski, M. and Lebuda, I., 2016. The big five, the huge two, and creative self-beliefs: A meta-analysis. Psychology of Aesthetics, Creativity, and the Arts [e-journal], 10(2), pp.214-232. doi: 10.1037/aca0000035.

Karwowski, M., Lebuda, I., Wisniewska, E., and Gralewski, J., 2013. Big five personality traits as the predictors of creative self-efficacy and creative personal identity: Does gender matter? The Journal of Creative Behavior [e-journal], 47(3), pp.215-232. doi: 10.1002/jocb.32.

Kaspi-Baruch, O., 2017. Big Five personality and creativity: the moderating effect of motivational goal orientation. The Journal of Creative Behavior [ejournal], 53(3), pp.325-338. doi: 10.1002/jocb.183.

Kaufman, J.C. and Beghetto, R.A., 2013. Do people recognize the four Cs? Examining layperson conceptions of creativity. Psychology of Aesthetics, Creativity, and the Arts [e-journal], 7(3), pp.229-236. doi: 10.1037/a0033295.

Kaufman, J.C. and Sternberg, R.J., 2010. The Cambridge Handbook of Creativity. Cambridge University Press.

Maxwell, S.E., Lau, M.Y. and Howard, G.S., 2015. Is psychology suffering from a replication crisis? What does "failure to replicate" really mean? American Psychologist [e-journal], 70(6), pp.487-498. doi: 10.1037/a0039400.

Puryear, J.S., Kettler, T. and Rinn, A.N., 2017. Relationships of personality to differential conceptions of creativity: A systematic review. Psychology of Aesthetics, Creativity, and the Arts [e-journal], 11(1), pp.59-68. doi: 10.1037/aca0000079.

Raja, U. and Johns, G., 2010. The joint effects of personality and job scope on inrole performance, citizenship behaviors, and creativity. Human Relations [ejournal], 63(7), pp.981-1005. doi: 10.1177/0018726709349863.

Silvia, P.J., Beaty, R.E., Nusbaum, E.C., Eddington, K.M., Levin-Aspenson, H. and Kwapil, T.R., 2014. Everyday creativity in daily life: An experiencesampling study of "little c" creativity. Psychology of Aesthetics, Creativity, and the Arts [e-journal], 8(2), pp.183-188. doi: 10.1037/a0035722.

Soto, C.J. and John, O.P., 2009. Ten facet scales for the Big Five Inventory: Convergence with NEO PI-R facets, self-peer agreement, and discriminant validity. Journal of Research in Personality [e-journal], 43(1), pp.84-90. doi: 10.1016/j.jrp.2008.10.002.

Stock, R.M., von Hippel, E. and Gillert, N.L., 2016. Impacts of personality traits on consumer innovation success. Research Policy [e-journal], 45(4), pp.757-769. doi: 10.1016/j.respol.2015.12.002.

Sung, S.Y. and Choi, J.N., 2009. Do big five personality factors affect individual creativity? The moderating role of extrinsic motivation. Social Behavior and Personality: An International Journal [e-journal], 37(7), pp.941-956. doi: 10.2224/sbp.2009.37.7.941. 
Zhao, H. and Seibert, S.E., 2006. The big five personality dimensions and entrepreneurial status: A meta-analytical review. Journal of Applied Psychology [e-journal], 91(2), pp.259-271. doi: 10.1037/0021-9010.91.2.259.

\section{ABOUT AUTHORS}

Michal Jirásek - (M.J.) Masaryk University, Faculty of Economics and Administration, Brno, Czech Republic, Department of Corporate Economics, Assist. Prof., e-mail: mijirasek@mail.muni.cz, Author's ORCID: 0000-00020407-4045.

František Sudzina - (F.S.) Aalborg University, Faculty of Engineering and Science, København SV, Denmark, Department of Materials and Production, Assoc. Prof., e-mail: sudzina@business.aau.dk, Author's ORCID: 0000-00031867-9237.

\section{AUTHOR CONTRIBUTIONS}

F.S. - initial conceptualization and data collection; M.J. - analysis, writing and editing the paper.

\section{CONFLICTS OF INTEREST}

The authors declare no conflict of interest. The funders had no role in the design of the study; in the collection, analyses, or interpretation of data; in the writing of the manuscript, or in the decision to publish the results. 


\section{APPENDIX}

BFI-44 Personality inventory

For calculating personality traits we used following combinations of items below (note that "R" labels reverse-scored items):

- Extraversion: 1, 6R, 11, 16, 21R, 26, 31R, 36;

- Agreeableness: 2R, 7, 12R, 17, 22, 27R, 32, 37R, 42;

- Conscientiousness: 3, 8R, 13, 18R, 23R, 28, 33, 38, 43R;

- Neuroticism: 4, 9R, 14, 19, 24R, 29, 34R, 39;

- Openness to Experience: 5, 10, 15, 20, 25, 30, 35R, 40, 41R, 44.

For calculating personality facets we used following combinations of items below (note that " $\mathrm{R}$ " labels reverse-scored items):

- Assertiveness (Extraversion): 1, 6R, 21R, 26, 31R;

- Activity (Extraversion): 11, 16;

- Altruism (Agreeableness): 7, 22, 27R, 32;

- Compliance (Agreeableness): 2R, 12R, 17;

- Order (Conscientiousness): 8R, 18R;

- Self-Discipline (Conscientiousness): 13, 23R, 28, 38, 43R;

- Anxiety (Neuroticism): 9R, 19, 34R, 39;

- Depression (Neuroticism): 4, 29;

- Aesthetics (Openness): 30, 41R, 44;

- Ideas (Openness): 10, 15, 25, 35R, 40.

I am someone who...

1. ... is talkative.

2. ... tends to find fault with others.

3. ... does a thorough job.

4. ... is depressed, blue.

5. ... is original, comes up with new ideas.

6. ... is reserved.

7. ... is helpful and unselfish with others.

8. ... can be somewhat careless.

9 .... is relaxed, handles stress well. 
10. ... is curious about many different things.

11. ... is full of energy.

12. ... starts quarrels with others.

13. ... is a reliable worker.

14. ... can be tense.

15. ... is ingenious, a deep thinker.

16. ... generates a lot of enthusiasm.

17. ... has a forgiving nature.

18. ... tends to be disorganized.

19. ... worries a lot.

20. ... has an active imagination.

21. ... tends to be quiet.

22. ... is generally trusting.

23. ... tends to be lazy.

24. ... is emotionally stable, not easily upset.

25. ... is inventive.

26. ... has an assertive personality.

27. ... can be cold and aloof.

28. ... perseveres until the task is finished.

29. ... can be moody.

30. ... values artistic, aesthetic experiences.

31. ... is sometimes shy, inhibited.

32. ... is considerate and kind to almost everyone.

33. ... does things efficiently.

34. ... remains calm in tense situations.

35. ... prefers work that is routine.

36. ... is outgoing, sociable.

37. ... is sometimes rude to others.

38. ... makes plans and follows through with them.

39. ... gets nervous easily.

40. ... likes to reflect, play with ideas. 
41. ... has few artistic interests.

42. ... likes to cooperate with others.

43. ... is easily distracted.

44. ... is sophisticated in art, music, or literature.

(C) 2020 by the authors. Submitted for possible open access publication under the terms and conditions of the Creative Commons Attribution (CC-BY) license (http://creativecommons.org/licenses/by/4.0/). 